\title{
CORRIGENDUM
}

\section{Service providers' perceptions of working in residential aged care: a qualitative cross-sectional analysis - CORRIGENDUM}

\author{
MICHELLE K. BENNETT, ELIZABETH C. WARD, \\ NERINA A. SCARINCI and MONIQUE C. WAITE
}

doi:10.1017/So144686X14000853, published online by Cambridge University Press, 1 August 2014.

In this article the following errors occurred:

1. In the final paragraph of the Introduction in the third line the words "to maintain consistency in terminology" were added in error. The sentence should read ... Whilst it is accepted that achieving positive multi-disciplinary interaction is a complex endeavour, to date, the specific factors influencing multidisciplinary interaction and collaboration within the unique RACF environment have not been fully examined....

2. In the reference list, Bard, T. R., Lowenstein, N. A. and Satin, D. G. is dated (2000) it should be (2009). The reference is correct in the article text.

3. In the reference list Blackford, J., Strickland, E. and Morris, B. should read Morris, B., Blackford, J. and Strickland, E.

4. In the text, page 17 , Discussion, third paragraph, line 3 the text reference should read ... (Morris, Blackford and Strickland 2007;...

5 . In the text, page four, Introduction, second last paragraph the reference Trinka and Clark (2009) should be Trinka and Clark (2000) and in the reference list it should be Trinka, T. J. K. and Clark, P. G. 2000....

\section{Reference}

Bennett, M. K. et al. 2014. Service providers' perceptions of working in residential aged care: a qualitative cross-sectional analysis. Ageing and Society, published by Cambridge University Press, 1 August 2014. doi:10.1017/So144686X14000853. 